\title{
Blended Learning Innovation Model among College Students Based on Internet
}

\author{
https://doi.org/10.3991/ijet.v13i10.9454 \\ Jia Zhang \\ Suqian College, Suqian, China \\ 30440174 @qq. com
}

\begin{abstract}
In general, over $70 \%$ of students can adapt to this blended learning model after experiencing the blended learning model for some time, which can satisfy the individual differences of students in a better way, attain some assistance from it and help to improve learning performance and learning ability. It can be discovered from this research that the blended learning model is superior to the single and traditional teaching mode or the pure network teaching mode in the aspects of inspiring the learning interest of students, exercising self-management capability of students and self-evaluation ability. It can be seen from the specific situation of investigation data that it is feasible to implement the blended learning model in colleges and universities even though the overall level of students' ability in the blended learning is low. As this is a preliminary investigation into the blended learning model, specific solutions or strategies have not been provided for some problems. However, it is believed to achieve greater effects if the research is continued on the practice.
\end{abstract}

Keywords-Teaching-learning-research; blended learning innovation model; college students

\section{Introduction}

The 21st century is an era of life-long learning in society [1]. Information technology focusing on network communication technology and multimedia technology is changing our living environment and lifestyle [2-4]. College students are the future of society who are shouldering the heavy responsibility of constructing the future of the country. Network independent learning is one of the essential qualities for the new generation of college students, and the ability of network independent learning determines the adaption ability to the society. At school, the blended learning model is produced in such an environment, which has changed the learning style and thinking of college students, especially by providing many excellent education resources to higher education, broking the time and spatial restrictions in education and providing opportunities of fair education to more students [5-6]. More and more educators pay attention to the development and function of the blended learning model and it has become the most popular education concept currently [7]. 


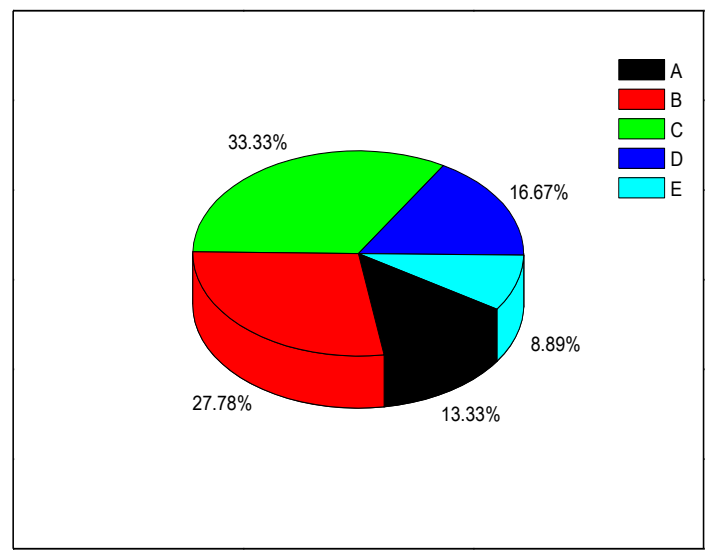

Fig. 1. College students' network autonomous learning of the five variables of ability is to grade distribution

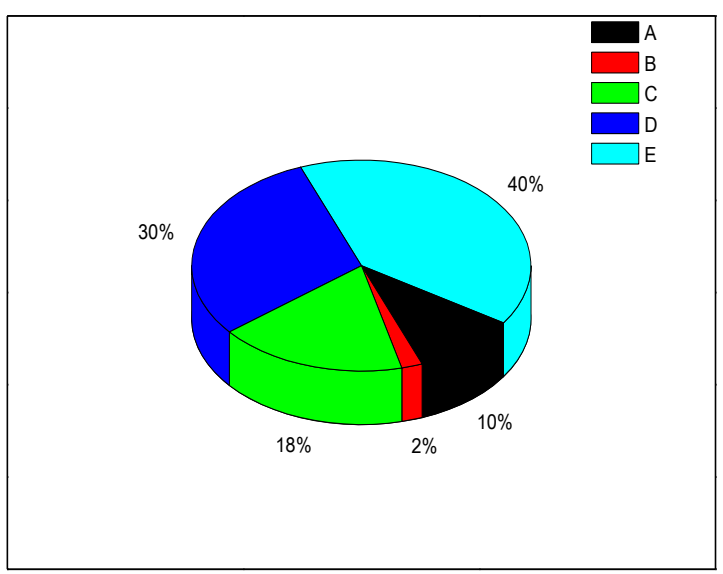

Fig. 2. College students' network autonomous learning management ability level of eight variables in the visual map

\section{$2 \quad$ Modes of Blended Learning}

This paper has studied college students who have just started college life after national entrance examination, possessed with certain learning ability and self-control, can accept and adapt to new things quickly and can provide more detailed and accurate information for research [8-10]. The research objects are sixty students from class A and class B, freshmen of the school of software in Changchun University, among whom the blended learning model teaching has been implemented. This experiment took one semester and included 42 classes in total [11-14]. The questionnaire has been completed among them at the end of the semester [15]. 
The blended learning model is a descriptive method used to present the blended learning process clearly and clarify each learning process [16-19]. There are several modes of blended learning, including the skill-driven mode, attitude-driven mode, ability-driven mode and Barnum and Paannaxm mode [20-22]. The skill-driven mode combines self-learning at the student's own pace with online guiding of a teacher, where the learners and teachers mainly interact with self-paced learners through email and an online forum [23]. The attitude-driven mode is a combination of traditional class learning and online collaborative learning, which explains the content, property, expected results of collaborative learning in a face-to-face manner as well as related matters of how to adopt network technology to make collaboration to the learners [24]. This includes formation of attitudes and behavior. The ability-driven mode is where the learners and experts act together and make online interaction to attain knowledge [25]. The decision-making process is guided by basic facts and working principles, but also needs to be equipped with knowledge which is possessed by experts [26-28]. The abilitydriven mode is a blended learning mode suitable for knowledge learning [29-30]. Investigation and Analysis of the Current Situation of Online Independent Learning Ability among College Students in the Blended Learning Mode

Table 1. Factor analysis intercommunity results

\begin{tabular}{|l|l|l|}
\hline & Initial & Extraction \\
\hline The first question & 1.000 & 0.632 \\
\hline The second question & 1.000 & 0.774 \\
\hline The third question & 1.000 & 0.625 \\
\hline The forth question & 1.000 & 0.754 \\
\hline The fifth question & 1.000 & 0.825 \\
\hline The sixth question & 1.000 & 0.784 \\
\hline The seventh question & 1.000 & 0.662 \\
\hline The eighth question & 1.000 & 0.889 \\
\hline The ninth question & 1.000 & 0.895 \\
\hline The tenth question & 1.000 & 0.745 \\
\hline The eleventh question & 1.000 & 0.658 \\
\hline The twelfth question & 1.000 & 0.664 \\
\hline The thirteenth question & 1.000 & 0.714 \\
\hline The fourteenth question & 1.000 & 0.621 \\
\hline The fifteenth question & 1.000 & 0.646 \\
\hline The sixteen question & 1.000 & 0.636 \\
\hline The seventeen question & 1.000 & 0.614 \\
\hline The eighteen question & 1.000 & 0.675 \\
\hline
\end{tabular}


Table 2. College students' network autonomous learning overall analysis

\begin{tabular}{|l|c|c|c|c|c|c|c|}
\hline \multirow{2}{*}{\multicolumn{1}{|c|}{ Project }} & \multicolumn{5}{c|}{ Level } & \multirow{2}{*}{ Average } & $\begin{array}{c}\text { Standard } \\
\text { deviation }\end{array}$ \\
\cline { 2 - 8 } & $\boldsymbol{A}$ & $\boldsymbol{B}$ & $\boldsymbol{C}$ & $\boldsymbol{D}$ & $\boldsymbol{E}$ & & 0.8212 \\
\hline The second question & 10.24 & 45.25 & 34.64 & 0 & 5.694 & 3.1254 & 0.6667 \\
\hline The fifth question & 15.37 & 64.54 & 15.91 & 13.21 & 2.18 & 3.2102 & 0.625 \\
\hline The seventh question & 0 & 8.23 & 69.31 & 2.22 & 0 & 2.7125 & 0.5142 \\
\hline The twelfth question & 16.55 & 40.58 & 40.21 & 0 & 2.71 & 3.6524 & 0.8512 \\
\hline The thirteenth question & 2.71 & 24.58 & 62.14 & 5.48 & 5.12 & 3.1020 & 0.7874 \\
\hline
\end{tabular}

\subsection{Investigation data analysis}

The Bamum and Panmnalm mode includes four stages, which include learning material transfer based on the Internet, face to face processing, formation of certain products and cooperative extension learning. Teachers and students can design and form a special blended learning mode based on the requirements of learning content and with a combination of the teaching experience [31-33]. The blended learning mode studied in this paper is designed and formed with a combination of partial advantages of the attitude-driven mode as well as the Bamum and Paannann mode and also the needs of learning content. This paper makes research on the development ability of students in online independent learning in the blended learning mode [34].

There are totally 60 copies of the questionnaire sent out with 37 valid questionnaires collected and the collection rate is $61.67 \%$, among which there are 28 boys and 9 girls. The reason for the low collection rate is that some students do not realize the importance of network independent learning to their own development, so they did not submit the questionnaires. Furthermore, some students did not attend the class on time and missed the time for questionnaire.

In this investigation, this paper has made the hypothesis in advance for three possible dimensions, or factors, based on related literature and theory, and the questionnaires were sent out for investigation and the hypothesis was checked for correctness with the adoption of factor analysis method.

The data in this paper was tested for suitability for applied factor analysis through $\mathrm{KMO}$ and Bartlett.s sphericity test and the results show that $\mathrm{KMO}>0.7$, which indicates that this experimental data is more sui Statistical data in table 2 for factor analysis. The significance level reaches 0.001 , indicating that there are common factors among correlation matrixes [35-36].

The commonality of each variable through principle component analysis and the results of the test for effectiveness of factor selection are shown in Table 1. In the principle component analysis, the quantity of principle components is consistent with the quantity of original variables, as shown in Tables III and IV. 


\section{Investigation and Analysis of the Current Situation of Online Independent Learning Ability among College Students in the Blended Learning Mode}

\subsection{Investigation data analysis}

The Bamum and Panmnalm mode includes four stages, which include learning material transfer based on the Internet, face to face processing, formation of certain products and cooperative extension learning. Teachers and students can design and form a special blended learning mode based on the requirements of learning content and with a combination of the teaching experience [31-33]. The blended learning mode studied in this paper is designed and formed with a combination of partial advantages of the attitude-driven mode as well as the Bamum and Paannann mode and also the needs of learning content. This paper makes research on the development ability of students in online independent learning in the blended learning mode [34].

There are totally 60 copies of the questionnaire sent out with 37 valid questionnaires collected and the collection rate is $61.67 \%$, among which there are 28 boys and 9 girls. The reason for the low collection rate is that some students do not realize the importance of network independent learning to their own development, so they did not submit the questionnaires. Furthermore, some students did not attend the class on time and missed the time for questionnaire.

In this investigation, this paper has made the hypothesis in advance for three possible dimensions, or factors, based on related literature and theory, and the questionnaires were sent out for investigation and the hypothesis was checked for correctness with the adoption of factor analysis method.

The data in this paper was tested for suitability for applied factor analysis through $\mathrm{KMO}$ and Bartlett.s sphericity test and the results show that $\mathrm{KMO}>0.7$, which indicates that this experimental data is more suitable for factor analysis. The significance level reaches 0.001 , indicating that there are common factors among correlation matrixes [3536].

The commonality of each variable through principle component analysis and the results of the test for effectiveness of factor selection are shown in Table 1. In the principle component analysis, the quantity of principle components is consistent with the quantity of original variables, as shown in Tables III and IV.

The initial commonality of each variable is 1 and column Extraction is the variable commonality after extraction [37-38]. The data in the table proves that the former hypothesis is correct. This paper has made investigation and research on the network independent learning ability of college students in the blended learning model through three dimensions, or factors. Questions 2, 5, 7, 12, 13 investigate the self-preparation ability of students in network independent learning. Questions 3, 6, 9, 10,11,14, 15 and smart questions investigate the self-management ability of students in network independent learning. Questions 1, 4, 8, 17, 18 investigate the self-evaluation ability of students in network independent learning. Detailed content is shown in Table 1[39]. 
Table 3. College students' network autonomous learning management overall analysis

\begin{tabular}{|c|c|c|c|c|c|c|c|}
\hline \multirow{2}{*}{ Project } & \multicolumn{5}{|c|}{ Level } & \multirow{2}{*}{ Average } & \multirow{2}{*}{$\begin{array}{c}\text { Standard de- } \\
\text { viation }\end{array}$} \\
\hline & $A$ & $B$ & C & $D$ & $E$ & & \\
\hline The third question & 0 & 10.23 & 51.26 & 39.56 & 0 & 3.3263 & 0.6253 \\
\hline The sixth question & 0 & 25.12 & 55.36 & 19.58 & 0 & 3.2626 & 0.6451 \\
\hline The ninth question & 5.25 & 36.25 & 62.12 & 0 & 2.47 & 3.1410 & 0.8251 \\
\hline The tenth question & 2.70 & 41.26 & 41.29 & 21.23 & 0 & 3.3625 & 0.6210 \\
\hline The eleventh question & 2.70 & 35.21 & 59.62 & 0 & 2.70 & 3.3261 & 0.6765 \\
\hline
\end{tabular}

Table 4. College students' network autonomous learning self-assessment ability analysis

\begin{tabular}{|l|c|c|c|c|c|c|c|}
\hline \multirow{2}{*}{\multicolumn{1}{|c|}{ Project }} & \multicolumn{5}{c|}{ Level } & \multirow{2}{*}{ Average } & $\begin{array}{c}\text { Standard } \\
\text { deviation }\end{array}$ \\
\cline { 2 - 7 } & $\boldsymbol{A}$ & $\boldsymbol{B}$ & $\boldsymbol{C}$ & $\boldsymbol{D}$ & $\boldsymbol{E}$ & & 0.7152 \\
\hline The first question & 16.23 & 54.12 & 27.15 & 2.70 & 0 & 3.2652 & 0.9123 \\
\hline The forth question & 21.25 & 5.12 & 13.24 & 59.21 & 0 & 23.7451 & 0.6854 \\
\hline The eighth question & 0 & 24.15 & 68.25 & 5.48 & 2.70 & 3.1236 & 0.7125 \\
\hline The seventeen question & 2.70 & 24.45 & 59.85 & 10.89 & 2.70 & 3.3256 & 0.7141 \\
\hline The eighteen question & 2.70 & 29.45 & 59.64 & 5.24 & 2.70 & 3.5412 & \\
\hline
\end{tabular}

\subsection{Descriptive analysis}

In the network independent learning among college students, self-preparation ability is the basis which includes two aspects [40]. One is the attitude toward network independent learning and computer operation degree. The other is the preparation for the course itself, such as making a study plan based on their own practical situation.

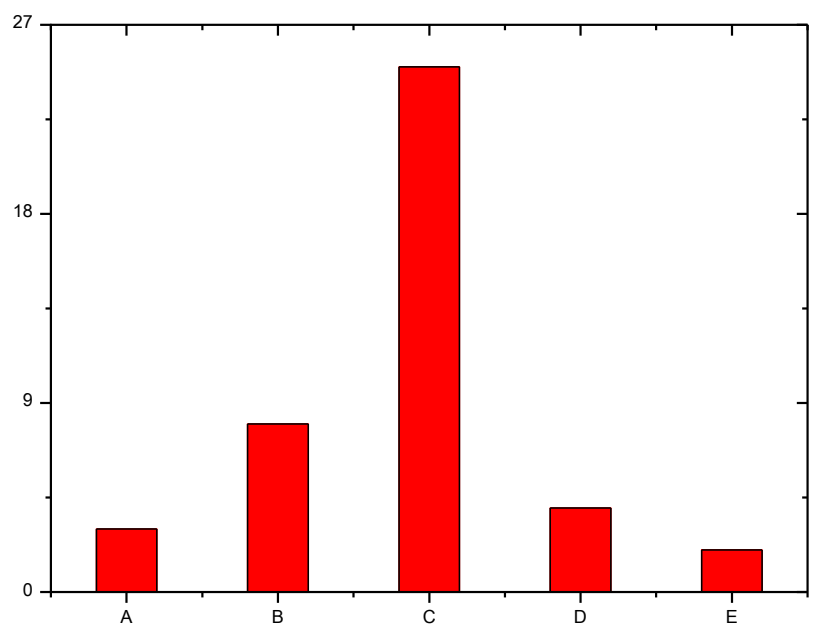

Fig. 3. Develop a plan of learning ability distribution 


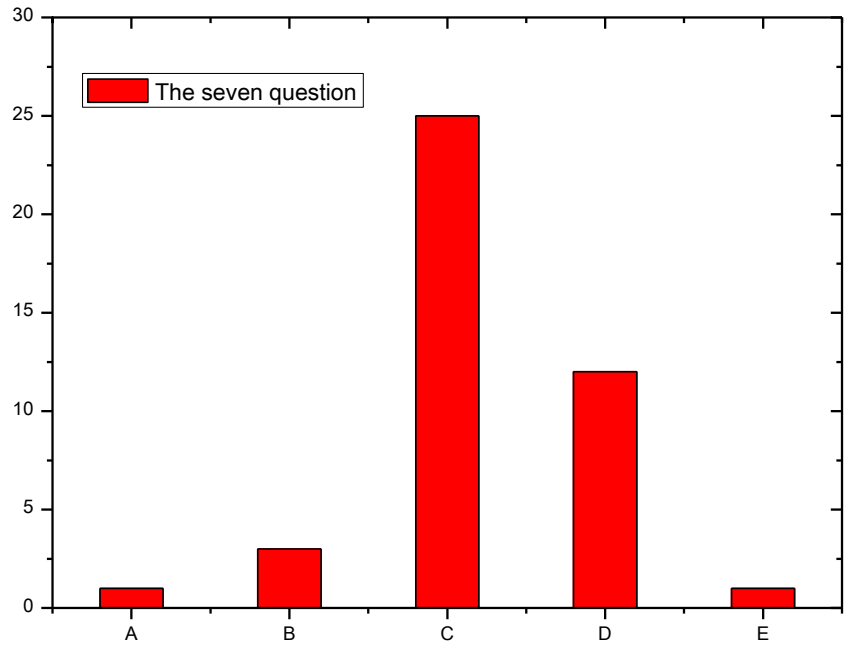

Fig. 4. Distribution of autonomous learning ability

Statistical data in Table 2 shows that $94.59 \%$ of college students can adapt to network independent learning, with an average score of $3.5675 .97 .3 \%$ of students can basically master the computer operation process, with an average score of 3.6557 , which indicates that there are not too many problems or difficulties in the attitude and practical operation among students [41]. However, the preparation ability for course learning itself is at the low level, with an average score of 2.9987. In the investigation, $10.82 \%$ of students cannot make a corresponding study plan and only $27.02 \%$ of students can make a corresponding study plan and most of the students proceed with their own feelings. $22.22 \%$ of students neglected to make independent preview and preparation before class. Specific content is shown in Table 2 [42].

Figure 1 presents the grade distribution map of five variables in the preparation ability of network independent learning among college students at the self-preparation stage. It can be seen from the figure that at the self-preparation stage, the students with a middle level ability exceed fifty percent and at the low level students account for less than $1 / 4$, which indicates that there is large room for improvement of ability through systematic cultivation.

\subsection{Self-management ability}

In blended learning, the richness and convenience of network learning resources provides convenience to the learners. At the same time, the learners are requested to possess strong management and control ability, which is the assurance for the students to make network study smoothly and is the key of constructing knowledge. The statistical data in Table 3 shows that the network study time of $64.86 \%$ of students per week are between two tablet times; $25.00 \%$ of students can finish the expected plan basically in the network independent learning and $35.14 \%$ of students can make adjustments for 
study time and progress in network independent learning. The network trek phenomenon happened to $100 \%$ of students in network independent learning, which indicates that the self-control ability of students is weak. In network independent learning, the emotional control ability of students is at a general level, which is 3.5135 on average. They are also weak in the management of the study method, which is 3.33784 on average. Details are as shown in Table 3.

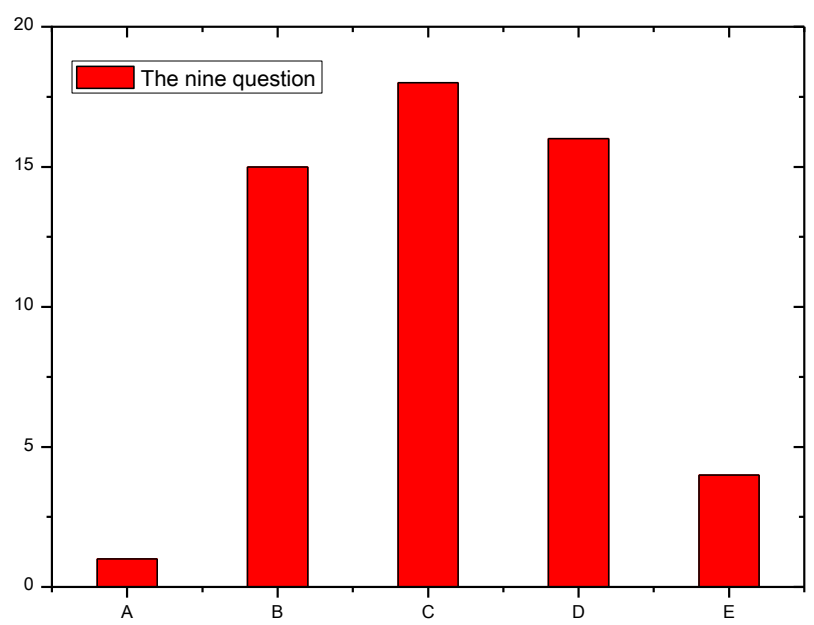

Fig. 5. Learning process management profile

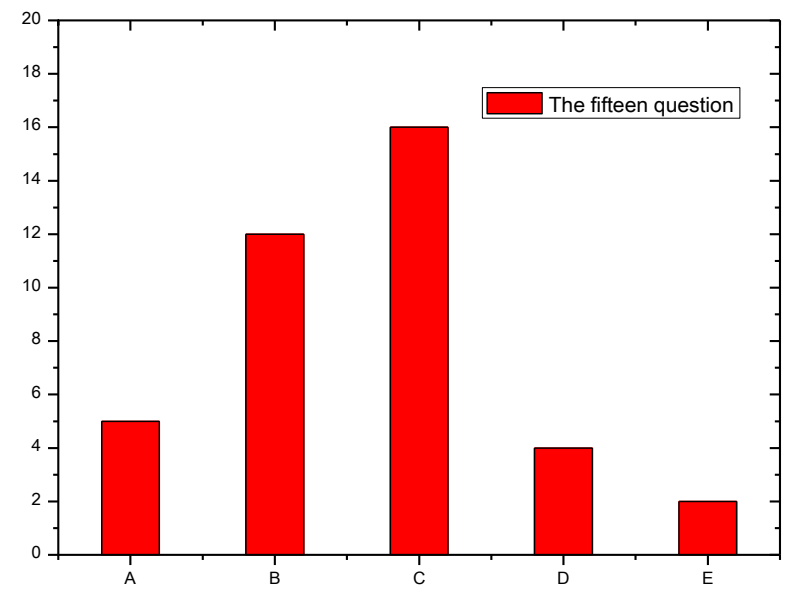

Fig. 6. Self-monitoring ability of management profile

Figure 3 presents the hierarchical visual distribution of eight variables in the management ability of network independent learning among college students at the selfmanagement stage. It can be seen from the figure that students at $\mathrm{C}$ level accounts for 
the most, close to $1 / 2$. The proportion of $E$ level decreases compared with the self-preparation stage, which explains that in the network independent learning among college students, most students can make the self-management but the degrees are different.

\subsection{Self-evaluation ability}

The analysis and reflection of learners for their network study situation is the mastering for their learning behavior and is the representation of responsibility for their own study, which can help the learners understand their mastered knowledge, check the realization degree of the study plan and study objectives, take timely measures for the gap and shortages in their learning stage to promote better learning.

Statistical data in Table 4 shows that after experiencing one semester of the blended learning model, only $16.22 \%$ of students adapt to network independent learning completely, and $21.62 \%$ of students can understand their study level clearly. The level of making a summarized evaluation for their own learning situation reasonably and objectively after learning is generally with the average score of 3.1351 . Only $2.70 \%$ of students can check the planned implementation situation and analyze the advantages and shortages in network learning and also propose suggestions for subsequent network study. Details are shown in Table 4.

Figure 4 presents hierarchical visual distribution of five variables in the management ability of network independent learning among college students at the self-management stage. The figure shows that at the self-evaluation stage, the distribution of the selfevaluation ability of students at the A level clearly improves, which indicates that the self-cognition of college students is clear, although it may be lacking self awareness and a lack of self reflection.

\section{Summarization of Data Analysis}

\subsection{Summarization of self-preparation stage}

In the data investigation of the self-preparation section, there were six students who can master the basic operation of computer network technology proficiently among 37 investigated students. There were students who can generally grasp the operation of computer network technology and there was only one student who can master this skill, which indicates that college students have high mastering and application ability for computer at the moment and there is no major obstacle for network independent learning.

In the overall analysis process of self-preparation ability, the college students are weak in making a study plan and study objectives independently, which is mainly presented in question 5 and question 13. The average scores are 3.0000 and 3.1351, as shown in Figure 5. Therefore, the ability of students in making study plan independently in network independent learning must be strengthened.

In the overall ability analysis process, the independent preview ability of college students has the lowest score, regarding question 7 with an average score of 2.8611, as 
shown in Figure 6. The figure reveals that it is urgent to improve the network independent preview ability of college students. Nobody can keep the habit of making preview before network study all the time and most students are in the middle state, which is optional.

\subsection{Summarization of self-management stage}

In the data investigation of self-management section, it can be known through data statistics and analysis that the college students are weak in time management in network independent learning, with an average score of 3.0556, as shown in Figure 7. Students who can well manage their network time is less than $1 / 4$ and the time concept is not clear.

In the process of network independent learning, the experience among college students is serious and all the 37 students experienced network trek and network trek phenomenon appeared more or less, which indicates that the college students are weak in managing the study progress in network independent learning with an average score of 2.9189, as shown by the specific distribution in Figure 8 .

In the process of network independent learning, the self-monitoring ability of students is a key factor affecting the network study effect, which has been analyzed in detail in this research. It can be learnt from the results of question 15 and question 16 that the emotional control and method management of network independent learning among college students is at a relatively low level and needs to be further improved. The specific distribution is shown in Figure 9.

\section{Conclusion}

In general, over $70 \%$ of students can adapt to this learning model after experiencing the blended learning model for some time, which can satisfy the individual differences of students in a better way, attain some assistance from it and help to improve learning performance and learning ability. It can be discovered from this research that the blended learning model is superior to the single and traditional teaching modes as well as the only network teaching mode in the aspects of inspiring the learning interest of students, exercising the self-management ability of students and self-evaluation ability. It can be seen from the specific investigation data that it is feasible to implement the blended learning model in colleges and universities even though the overall level of students' ability of blended learning is low. As this is only a preliminary investigation into the blended learning model, specific solutions or strategies have not been provided for some problems. However, greater effects can be achieved with continued on the following aspects of the practice.

1. The students should pay attention to setting up a proper learning attitude, make a reasonable study plan and make a full preview of a course during the self-preparation stage in the network independent learning process, which are usually neglected by students in network independent learning. 
2. There are many factors involved in the self-management stage in the network independent learning process. This paper has studied some prominent aspects, such as management of study time, management of study progress, management of study activity and management of self-monitoring during study and proposed corresponding aspects that need attention or learning methods.

3. This paper has provided self-evaluation methods and reference tables for students based on the questionnaire results and with a combination of the characteristics of college students at the self-evaluation stage of network independent learning can help enable students to make self-evaluation effectively and independently in the network environment.

\section{References}

[1] Liang, B. (2011). Cross-cultural awareness in college English teaching. Applied Me-chanics and Materials, 599: 2011-2013, https://doi.org/10.4028/www.scientific.net/AMM.599$\underline{601.2011}$

[2] Sheulur, B. (1998). Higher education for the information age. Circuits and Devices Magazine, 14: 156-159, https://doi.org/10.1109/101.678952

[3] Zhang, F., You, M. (2011). Constructivism computer-assisted instruction model for college English study. Communications in Computer and Information Science, 233: 200-206. https://doi.org/10.1007/978-3-642-24010-2 27

[4] Zhang, F. (2014). Computer aided design of Chinese college English teaching materials based on COCA corpus. Applied Mechanics and Materials, 59: 916-919, https://doi.org/10.4028/www.scientific.net/AMM.590.916

[5] Athula, G., Tamara, G. (2012). Impact of information technology on delivery of educa-tion. IEEE Region 10 Annual International Conference. Proceedings of TENCON, 8: 62-69, https://doi.org/10.1109/TENCON.1998.797085

[6] Segpo, H., Perth, M. (2000). Response of -Finnish higher education institutions to the national information society programme. High Education Policy, 13: 233-236.

[7] Çırak Kurt, S., \& Yıldırım, İ. (2018). The students' perceptions on blended learning: A Q method analysis. Educational Sciences: Theory \& Practice, 18(2), 427-446. https://doi.org/10.12738/estp.2018.2.0002

[8] Nancy, H. (2010). Education: A key partner is the information system knowledge supply chain. Proceedings of the ACM SIGCPR Conference, 12: 412-416, https://doi.org/10.1145/ $\underline{299513.299712}$

[9] Latchman, H.A., Salzmarua, S., Denis, G. (1999). Information technology chanced learning in distance and conventional education. IFFF Transaction on Education, 15(8): 236-241, https://doi.org/10.1109/13.804528

[10] Wu, J. (2015). Based on the cross-cultural perspective of the change of English teach-ing research in China. Proceedings - 2015 International Conference on Intelligent Transportation, Big Data and Smart City, 164-168. https://doi.org/10.1109/ICITBS.2015.47

[11] Zhang, L. (2014). Analysis on English value and the effect of computer language. IT Transactions on Engineering Sciences, 87(4): 966-970. https://doi.org/10.2495/AMITP131181

[12] David, L., Zippy, E. (2001). Computer literacy and applications via distance e-learning. Computers and Education, 36(5): 421-423, https://doi.org/10.1016/S0360-1315(01)00022$\underline{7}$ 
[13] Gordon, M. (2014). Innovative education: Applications and management of infor-mation technology. Proceedings-Annual Meeting Decision Sciences Institute, 1(2): 236-245.

[14] Tina, M. (2014). Application of computer multimedia technology on English teaching. WIT Transactions on Engineering Sciences, 87(8): 947-952.

[15] Yang, Q.H. (2013). Research of college English teaching based on computer network technology. Lecture Notes in Electrical Engineering, 206(6): 375-382. https://doi.org/10.1007/ 978-1-4471-4790-9 48

[16] Ashra, S. (1999). Advanced technological education project to prepare information technology for the 21th century. Proceedings-Frontiers in Education Conference, 2(5): 23-28.

[17] Wang, Y. (2010). Research on human-computer interaction of English teaching at lo-cal area network. ICCASM 2010 - 2010 International Conference on Computer Appli-cation and System Modeling, 2(5): 2718-2722.

[18] Song, J. (2011). The English teaching model of cooperative learning in the network environment in higher vocational education. Communications in Computer and In-formation Science, 218: 100-104. https://doi.org/10.1007/978-3-642-23357-9 19

[19] Sun, Q.L. (2015). Information under the network environment using computer infor-mation security technology. Proceedings-2015 International Conference on Intelligent Transportation, ICITBS 2015, 474-477.

[20] Xu, M.Q. (2011). The research on out-of-class autonomous English learning in com-puterand network-assisted environment. Advances in Intelligent and Soft Compu-ting, 36: 453459. https://doi.org/10.1007/978-3-642-24775-0 71

[21] Yang, D.L., Zheng, H. (2010). Research on the framework of new college English teaching mode integrating cooperative and autonomous learning in the network mul-timedia environment. ICETC 2010-2010 2nd International Conference on Education Technology and Computer, 3: 3256-3259.

[22] Zhou, J., Chen, X.H. (2014). Analysis and simulation of computer virus propagation models in the network environment. Advanced Materials Research, 204: 433-436.

[23] Zhang, P. (2012). Analysis on the development of computer basic education under network environment. TEIN 2012-2012 3rd International Conference on Telecommu-nication and Information, 11: 137-141.

[24] Li, S. (2012). Multimedia computer assisted instruction in college English teaching. Proceedings-4th International Conference on Computational and Information Scienc-es, ICCIS 2012: 754-757.

[25] Shi, B. (2009). Empirical research on feasibility and effect of computer-aided College English teaching model. Proceedings-2009 International Conference on Information Engineering and Computer Science, ICIECS 2009: 258-261.

[26] Sun, R. (2012). Analysis of teacher role in computer-based English teaching. Commu-nications in Computer and Information Science, 267: 458-463. https://doi.org/10.1007/978-3642-29084-8 71

[27] Tang, X. (2010). Integrating computer technologies into College English Teaching in China. 2010 International Conference on E-Health Networking. Digital Ecosystems and Technologies, EDT 2010: 371-374.

[28] Chen, X.H. (2014). The research on English autonomous learning monitoring theory and application in the network environment. Applied Mechanics and Materials, 12: 6079-6082. https://doi.org/10.4028/www.scientific.net/AMM.644-650.6079

[29] Han, S.F., Miao, S. (2011). On college English teaching of writing in the network environment. 2011 International Conference on Multimedia Technology, ICMT 2011: 588-590. https://doi.org/10.1109/ICMT.2011.6002176 
[30] Li, S. (2011). Survey research on college students' English learning anxiety in the computer network environment. ICCSE 2011-6th International Conference on Com-puter Science and Education, 36: 1010-1012.

[31] Song, J. (2011). The English teaching model of cooperative learning in the network environment in higher vocational education. Communications in Computer and In-formation Science, 218: 100-104. https://doi.org/10.1007/978-3-642-23357-9 19

[32] Sun, Q.L. (2015). Information under the network environment using computer infor-mation security technology. Proceedings-2015 International Conference on Intelligent Transportation, ICITBS 2015: 474-477.

[33] Xu, M.Q. (2011). The research on out-of-class autonomous English learning in com-puterand network-assisted environment. Advances in Intelligent and Soft Compu-ting, 36: 453459. https://doi.org/10.1007/978-3-642-24775-0 71

[34] Yang, D.L., Zheng, H. (2010). Research on the framework of new college English teaching mode integrating cooperative and autonomous learning in the network mul-timedia environment. ICETC 2010-2010 2nd International Conference on Education Technology and Computer, 3: 3256-3259.

[35] Zhou, J., Chen, X.H. (2014). Analysis and simulation of computer virus propagation models in the network environment. Advanced Materials Research, 204: 433-436.

[36] Zhang, P. (2012). Analysis on the development of computer basic education under network environment. TEIN 2012-2012 3rd International Conference on Telecommu-nication and Information, 11: 137-141.

[37] Wang, Y. (2010). Research on human-computer interaction of English teaching at lo-cal area network. ICCASM 2010 - 2010 International Conference on Computer Appli-cation and System Modeling, 2(5): 2718-2722.

[38] Shen, L. (2011). Survey research on college students' English learning anxiety in the computer network environment. ICCSE 2011-6th International Conference on Com-puter Science and Education, Final Program and Proceedings, 11: 1010-1012.

[39] Wei, S.J., Qing, Z. (2013). On English for specific purposes in college English educa-tion through network technology. Proceedings - 3rd International Conference on In-strumentation and Measurement, Computer, Communication and Control, IMCCC 2013: 1146-1149.

[40] Sujua, W. (2013). Research on college English autonomous learning mode based on computer networks. Lecture Notes in Electrical Engineering, 227(5): 739-744.

[41] Hua, Y.Q. (2013). Research of college English teaching based on computer network technology. Lecture Notes in Electrical Engineering, 206(4): 375-382.

[42] Li, Z.Q. (2014). Higher vocational college "Computer network technology" course life scene design. Applied Mechanics and Materials, 65: 1848-1851.

\section{Author}

Jia Zhang, female, from Zhenjiang, Jiangsu Province, Art and Media College of Suqian College, counselor, lecturer and graduate student. Research Direction: Ideological and Political Education of College Students.

Article submitted 13 July 2018. Resubmitted 30 July 2018. Final acceptance16 August 2018. Final version published as submitted by the author. 